\title{
Toxic Effects of Chronic Chlorpyrifos Exposure on Jejunum of Adult Male Albino Rats and the Possible Ameliorative Role of Propolis
}

\author{
Yara M. El-fakharany and Omaima I. Abdel Hamid ${ }^{1}$
}

${ }^{1}$ Forensic Medicine \& Clinical Toxicology Department, Faculty of Medicine, Zagazig University, Al sharqia, Egypt

\begin{abstract}
Chlorpyrifos (CPF), as an extensively used organophosphorus pesticide, has many toxic hazards on health. There is a lack of data regarding the toxic effect of CPF on Gut. Aim of the work: to investigate the toxic effect of chronic oral exposure to chlorpyrifos on jejunum of adult male albino rats and to evaluate the ameliorative role of propolis. Methodology: The study extended for 12 weeks and included fifty male albino rats that were divided into 4 groups as follows: control group (I) consisted of 20 rats equally and randomly subdivided into 2 subgroups: Ia (-ve control) \& Ib (+ve control). propolis group (II) 10 rats treated with $400 \mathrm{mg} / \mathrm{kg}$ body weight of propolis dissolved in corn oil by oral gavage. chlorpyrifos group (III): 10 rats treated with CPF at a daily dose of $6.75 \mathrm{mg} / \mathrm{kg}$ $\{1 / 20$ of the oral LD50 of CPF (135mg/kg) $\}$ dissolved in corn oil. CPF+propolis group (IV) 10 rats each was gavaged orally with CPF (6.75 mg/kg body weight) with simultaneous administration of propolis ( $400 \mathrm{mg} / \mathrm{kg}$ body weight) once daily. The levels of serum citrulline, circulating endotoxin core antibodies (Endocab IgG) were assessed, GSH \& MDA in jejunal mucosa were measured. Histopathological and morphological analysis of the jejunal mucosa was also evaluated. Results: Significant decrease in serum citrulline level, increase Endocab IgG with a significant decrease in tissue GSH and increase in MDA in CPF group when compared with control and CPF+Propolis groups with disruption of jejunal epithelium and decrease in both height and width of villi. CPF+propolis group showed no significant difference in MDA levels when compared with control, but significant difference regarding other biochemical and histopathological parameters was detected on comparison

Keywords with CPF group. Conclusion: CPF induced disruption and increased permeability of epithelial barrier in the jejunum with bacterial translocation and chronic endotoxemia evidenced by Endocab IgG. This may be due to induction of oxidative stress. Propolis as a natural, cheap and available product could partially ameliorate the toxic effect of CPF on jejunum.
\end{abstract}

Chlorpyrifos, Propolis, Jejunum, toxicity, Endocab, Citrulline

\footnotetext{
Introduction

7 hlorpyrifos (CPF) [0, 0- diethyl 0-(3, 5, 6tricloro-2- pyridinol) phosphorothionate] is a broad spectrum chlorinated organophosphorus insecticide, utilized extensively in agricultural and nonagricultural settings throughout the world. It was first manufactured by Dow Elanco company in the USA and introduced into the American market in 1965 (Eaton et al., 2008). Despite its restriction by the United States Environmental Protection Agency since 2000 due to its toxicity, it continues to be used to control crop damage from insects in agriculture worldwide (Elelaimy et al., 2012). The public is
}

exposed to CPF on a regular basis at chronic low levels from food and water contamination, dermal contact and inhalation (Busby et al., 2004). The Residual levels of pesticides in Egyptian foods are often higher than those found in developed countries, because of inadequate enforcement of laws concerning pesticide use and inadequate financial resources (Abdelaziz et al., 2010). Chlorpyrifos has been reported to elicit a number of toxic effects, including hematological (Goel et al., 2006), immunological abnormalities (Elelaimy et al., 2012), genotoxicity (Sandhu et al., 2013), teratogenicity (Tian et al., 2005), neurotoxicity and 
neurobehavioral changes (Flaskos, 2009). The gastro intestinal tract is the first organ to come in contact with food contaminants. At the same time, the intestinal epithelium represents the first line of defense against exogenous agents such as food antigens, live bacteria, bacterial products and other agents present in the intestinal lumen (Condette et al., 2015). Excessive intestinal permeability to macromolecules leads to uncontrolled passage of antigens and start of intestinal inflammation and gastro intestinal diseases (Camilleri et al., 2012). Although, chlorpyrifos was found to increase intestinal permeability through an ex vivo model study (Cook and Shenoy, 2003), and an in vitro model (Tirelli et al., 2007), a little is known about the chronic in vivo effect of chlorpyrifos on the gastrointestinal tract.

Propolis (also known as bee glue), a natural product collected by honey bees from various plant sources, is composed of mainly polyphenols and flavonoids that exhibit a variety of pharmacological actions such as antioxidant, antimicrobial, antiinflammatory and anticancer (Khalil, 2006).

Thus the present study was done to investigate the toxic effect of chronic oral exposure to chlorpyrifos on jejunum of adult male albino rats and to evaluate the ameliorative role of propolis.

\section{Materials and methods \\ Chemicals}

Chlorpyrifos powder obtained from Sigma-Aldrich, Germany imported by Cairo Chemical Company.

Propolis capsule (400mg purified propolis) obtained from Martinez Nieto, S.A., Cartagena, Spain.

\section{Animals}

The present study was conducted in accordance with the international guidelines for animal research and after the approval of the Institutional Review Board on animal research at Faculty of Medicine, Zagazig University, Egypt.

Fifty adult male albino rats of average weight between 180-200 g were obtained from the animal house of Faculty of Medicine, Zagazig University. Before commencing experimentation, the animals were subjected to 10 days of a passive preliminary period in order to adapt themselves to their new environment, to ascertain their physical wellbeing and to exclude diseased animals. Food was offered in equal amounts to all rats in each cage, water was offered in separate clean containers.

\section{The rats were divided into three groups as follows:}

-Group I (control):- twenty rats included in this group and divided into 2 equal subgroups as follows:

-Group Ia (negative control):- 10 rats received only regular diet and tap water for 12 weeks to measure the basic parameters.

-Group Ib (positive control):- 10 rats, each was gavaged orally with $1 \mathrm{ml}$ corn oil (vehicle of CPF, propolis) once daily for 12 weeks.

-Group II (propolis):- 10 rats, each was gavaged orally with Propolis (400 $\mathrm{mg} / \mathrm{kg}$ body weight) dissolved in corn oil, once daily for 12 weeks (Bhadauria et al., 2008).
-Group III (chlorpyrifos):- 10 rats, each was gavaged orally with CPF at a daily dose of $6.75 \mathrm{mg} / \mathrm{kg}\{1 / 20$ of the oral LD50 of CPF $(135 \mathrm{mg} / \mathrm{kg})\}$ dissolved in corn oil for 12 weeks (Goel et al., 2005).

-Group IV (CPF+propolis):- 10 rats, each was gavaged orally with CPF (6.75 mg/kg body weight) with simultaneous administration of propolis $(400 \mathrm{mg} / \mathrm{kg}$ body weight) once daily for 12 weeks.

\section{Methods}

\section{I-Biochemical analysis:}

Twenty-four hours after the end of treatment in each group, venous blood samples were obtained from the retro- orbital plexus of anaesthetized animals, the blood was left for spontaneous coagulation and serum was separated for estimation of:

1. Serum Citrulline: as a biomarker for gut epithelial cell injury using Rat Citrulline ELISA kit Cusabio (catalog number CSB-E13414r). It was measured spectrophotometrically at a wave length of $450 \mathrm{~nm} \pm 2$ and the results were expressed in $\mathrm{nmol} / \mathrm{ml}$

2. Circulating endotoxin core antibody IgG (EndoCab): as an index for bacterial translocation using EndoCab ELISA kit Hycult biotech (catalog number HK504). Concentrations of endotoxin core antibodies were measured using microtiter wells coated with equimolar amounts of endotoxin roughlipopolysaccharides from four Gram-negative bacterial species. Anti-endotoxin-core antibodies were captured by the solid phase antigen. Peroxidase conjugated antiIgG antibody was bound to captured endotoxin-core antibodies. The peroxidase conjugated antibody react with the substrate, tetramethylbenzidine (TMB).The enzyme reaction was stopped by the addition of oxalic acid. The absorbance at $450 \mathrm{~nm}$ was measured with spectrophotometer and the results were expressed in EndoCab standard median-units IgG ( $\mathrm{Gmu} / \mathrm{ml})$

After obtaining venous blood samples, animals were sacrificed and part of jejunum was used for biochemical estimation of oxidative stress parameters while another part was prepared for histopathological examination and morphometric analysis.

\section{Oxidative stress in jejunal mucosal tissue:}

The jejunum was excised and profusely rinsed with 10$20 \mathrm{ml}$ of cold saline. The mucosa was obtained by gentle scraping with a spatula (Martensson et al., 1990).

1. Malondialdehyde (MDA): Concentrations of free MDA content, as indices of lipid peroxidation, in the defined jejunal mucosal samples were measured using Bioxytech MDA-586 Assay (Catalog number 21044). Samples were thawed, homogenized in phosphate buffer ( $\mathrm{pH}, 7.4)$, and then centrifuged at $4000 \mathrm{x} g$ for 10 minutes. Free MDA was assayed by its reaction with N-methyl-phenylindole to generate the chromophore product which was measured spectrophotometrically according to the manufacturer's instructions. The results were standardized relative to the protein concentration of the original Homogenate

2. Reduced glutathione (GSH): The jejunal mucosal tissues were homogenized in 5 volume of 5\% 5sulfosalicylic acid. The homogenates were centrifuged for $3 \mathrm{~min}$ at $10,000 \mathrm{x} \mathrm{g}$ at $40 \mathrm{C}$ and the supernatant 
solutions were immediately analyzed for total GSH by the GSH disulfide reductase 5,5'-dithiobis(2nitrobenzoic acid) recycling procedure (Tietze, 1969) Estimation of serum levels of citrulline, endocab IgG and levels of GPX \& MDA in jejunal mucosal tissue was performed in Biochemistry Department, Faculty of Medicine, Zagazig University.

\section{III- Histopathological and morphometrical analysis:}

Parts of jejunum of sacrificed rats were fixed in $10 \%$ formalin saline solution for histopathological examination after staining with haematoxylin and eosin according to Bancroft and Gamble (2002). The image analyzer computer system Leica Qwin 500 (Leica Ltd, Cambridge, UK) in the image analyzing unit of the Pathology department, Faculty of Dentistry, Cairo University, Egypt was used to estimate the following parameters: the height of the villus $(\mathrm{Hv})$ at magnification $\mathrm{x} 10$ and the width of the villus near the crypt (Wv) at magnification $\mathrm{x} 40$

The collected data were expressed at mean \pm sd, tabulated and statistically analyzed

\section{Results}

-Death rate: Two rats died in chlorpyrifos group while one rat died in $\mathrm{CPF}+$ propolis group.

-Biochemical parameters (serum citrulline \& endocab IgG) and Oxidative stress parameters in jejunal mucosa (GPX and MDA):

Statistical comparison among group Ia (-ve control), group Ib (positive control ;corn oil) and group II (propolis) as regard mean values of serum citrulline, Endocab IgG, oxidative stress markers (MDA,GSH) and morphometry measures (villi height and width) revealed no significant differences $(p>0.05)$, so we used negative control group (Ia) as a standard reference for comparison with other treated groups.

The results of the study revealed significant difference among -ve control, CPF and CPF+Propolyis groups regarding mean values of serum citrulline, Endocab (IgG), Tissue MDA and GSH when compared with ANOVA test $\left({ }^{*} \mathrm{P}<0.0001\right)$ (Table 1).

\section{Serum citrulline(nmol/ml) :}

Statistical comparison by Least significant difference (LSD) test among -ve control, chlorpyrifos and $\mathrm{CPF}+$ Propolyis groups revealed significant decrease in the mean values of serum citrulline in CPF group when compared with -ve control and $\mathrm{CPF}+$ propolyis groups $\left({ }^{\mathrm{a}} \mathrm{p}<0.0001\right)$ while there was a significant decrease in mean values of serum citrulline in $\mathrm{CPF}+$ Propolyis group when compared with -ve control group ( $\left.{ }^{\mathrm{b}} \mathrm{p}<0.05\right)$ (Table 1).

\section{Endocab (IgG)(Gmu/ml):}

There was a significant increase in the mean values of endocab (IgG) in CPF group when compared with -ve control group ( $\left.{ }^{\mathrm{c}} \mathrm{p}<0.0001\right)$. A significant decrease in the mean values of Endocab (IgG) in $\mathrm{CPF}+$ Propolyis group when compared with CPF group was detected while there was a significant increase in $\mathrm{CPF}+$ Propolyis when compared with -ve control group $\left({ }^{\mathrm{d}} \mathrm{p}<0.05\right)$ by LSD test(Table $\left.\mathbf{1}\right)$.

\section{MDA(pmol/mg protein):}

Statistical comparison by Least significant difference (LSD) test revealed significant increase in mean values of MDA in CPF group when compared with -ve control and $\mathrm{CPF}+$ Propolyis groups $\left({ }^{\mathrm{e}} \mathrm{p}<0.05\right)$ while there was no significant difference regarding mean values of MDA between -ve control and $\mathrm{CPF}+$ Propolyis groups $\left({ }^{\mathrm{f}} \mathrm{p}>0.05\right)$ (Table 1).

Reduced GSH( $\mu \mathrm{mol} / \mathrm{g})$ :

There was a significant decrease in the mean values of reduced GSH in CPF group when compared with - ve control group $\left({ }^{\mathrm{g}} \mathrm{p}<0.0001\right)$ while there was a significant increase in the mean values of GSH in $\mathrm{CPF}+$ Propolyis group when compared with CPF group and a significant decrease when compared with -ve control group $\left({ }^{\mathrm{h}} \mathrm{p}<0.05\right)$ (Table 1).

Histopathological and morphometrical results:

A strong negative correlation ( $\mathrm{r}=-0.8191$, $\mathrm{p}=0.005846$ ) between Jejunal GSH level and Circulating endotoxin core antibodies IgG (Endocab) was detected using Pearson correlation (fig 1).

Haematoxylin and eosin stained sections from jejunum of the control groups (Ia \& Ib) and the propolis group showed normal jejunal structure in the form of mucosa containing finger like villi that protrude into the lumen, they are lined by simple columnar epithelium with basal oval nucli and brush border. There are intersepted goblet cells. The submucosa is composed of connective tissue with blood vessels. The muscle layer appeared normal (Fig 2, 3).

While sections stained sections from jujunum of the CPF treated group showed disrupted villi with loss of epithelial cells and apparent vaculation and apoptotic darkly stained nucli. The muscle layer showed thickening and separation of muscle fibers (Fig 4, 5).

The CPF+propolis group showed partial improvement with less vauclation and pyknosis. Also, there was improvement in the muscle layer pathology detected in the chlorpyrifos treated group (Fig 6).

The statistical comparison among group Ia (ve control), group Ib (corn oil) and group II (propolis) as regard mean values of morphometry measures (villi height and width) revealed no significant differences ( $>0.05$ ), so we used negative control group (Ia) as a standard reference for comparison with other treated groups.

The results of the study revealed significant difference among -ve control, CPF and CPF+Propolyis groups regarding jejuna villi height and width when compared with ANOVA test $(* \mathrm{P}<0.0001)$ Table (2). LSD statistical comparison of mean values of jejunal villi height showed significant decrease in CPF group when compared with -ve control and CPF+Propolyis groups $\left({ }^{\mathrm{a}} \mathrm{P}<0.0001\right)$ while $\mathrm{CPF}+$ Propolyis group showed significant decrease when compared with -ve control group $\left({ }^{b} \mathrm{P}<0.05\right)$. A significant decrease regarding the mean values of jejuna villi width in $\mathrm{CPF}$ group when compared with -ve control and $\mathrm{CPF}+$ Propolyis groups were detected( $\left({ }^{\mathrm{P}}<0.001\right)$, while there was a significant decrease in $\mathrm{CPF}+$ Propolyis group when compared with -ve control group $\left({ }^{\mathrm{d}} \mathrm{P}<0.05\right)$ (Table 2). 


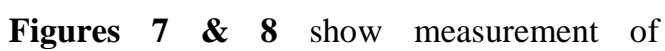
analyzer computer system Leica Qwin 500. intestinal villi height and width using the image

Table (1): Comparison among -ve control (Ia), chlorpyrifos (III) and CPF+propolis (IV) groups regarding mean values serum citrulline, endocab IgG, tissue MDA and GSH:

\begin{tabular}{|c|c|c|c|c|c|}
\hline Group & -ve control & $\begin{array}{c}\text { Chlorpyrifos } \\
\text { (CPF) }\end{array}$ & CPF+propolis & $\mathbf{f}$ & $\mathbf{p}$ \\
\hline Parameter & $\mathbf{N}=\mathbf{1 0}$ & $\mathbf{N}=\mathbf{8}$ & $\mathbf{N}=\mathbf{9}$ & & \\
\hline Serum Citrulline (nmol/ml) & $40.22 \pm 5.27$ & $23.67 \pm 0.34^{\mathrm{a}}$ & $35.92 \pm 2.24^{b}$ & 52.526 & $<0.0001^{*}$ \\
\hline Endocab (IgG)Gmu/ml & $90,77 \pm 1 \%, .0$ & $\begin{array}{c}138.21 \pm \\
11.33^{c}\end{array}$ & $\begin{array}{l}11 \wedge, \cdot r \pm \pm \\
14.03^{d}\end{array}$ & 18.1220 & $<0.0001^{*}$ \\
\hline MDA(pmol/mg protein) & $43.22 \pm 1.23$ & $90.25 \pm 8.66^{\mathrm{e}}$ & $40.19 \pm 2.13^{f}$ & 276.930 & $<0.0001^{*}$ \\
\hline GSH( $(\mu \mathrm{mol} / \mathrm{g})$ & $1.54 \pm 0.32$ & $0.92 \pm 0.16^{\mathrm{g}}$ & $1.19 \pm 0.01^{\mathrm{h}}$ & 21.095 & $<0.0001^{*}$ \\
\hline
\end{tabular}

$* P$ : Analysis of variance test (ANOVA). Least significant difference (LSD) ${ }^{a} P<0.0001 v s-v e$ control \& CPF+propolis groups, ${ }^{b} P<0.05$ vs - ve control group . ${ }^{c} P<0.0001 v s$-ve control group, ${ }^{d} P<0.05$ vs $-v e$ control \& chlorpyrifos groups, ${ }^{e} \mathrm{P}<0.05$ vs - ve control and $C P F+$ propolis groups, ${ }^{f} P>0.05$ vs - ve control group. ${ }^{g} P<0.0001 v s-v e$ control, ${ }^{h} P<0.05$ vs ve control \& chlorpyrifos groups

Table 2: Statistical comparison between morphometric measures of jejunal villi height and width among -ve control (Ia), chlorpyrifos (III) and CPF+propolis (IV) $\{$ mean \pm SD, $\mu \mathrm{m}\}$

\begin{tabular}{|c|c|c|c|c|}
\hline Group & -ve Control & $\begin{array}{r}\text { Chlorpyrifos } \\
\text { (CPF) }\end{array}$ & $\mathrm{CPF}+$ propolis & P value \\
\hline eter & $\mathbf{N}=10$ & $\mathbf{N}=\mathbf{8}$ & $\mathbf{N}=\mathbf{9}$ & \\
\hline Villi height & $320.22 \pm 135.27$ & $110.24 \pm 8.66^{\mathrm{a}}$ & $280.16 \pm 27.28^{b}$ & $<0.0001^{*}$ \\
\hline Villi width & $50.07 \pm 6.74$ & $28.64 \pm 2.03^{c}$ & $40.22 \pm 5.13^{d}$ & $<0.0001^{*}$ \\
\hline
\end{tabular}

*P: Analysis of variance test (ANOVA). Least significant difference (LSD); ${ }^{a} P<0.0001 v \mathrm{v}$ control \& CPF+propolis groups, ${ }^{b} P<0.05$ vs control, ${ }^{c} P<0.001$ vs control group\& $C P F+$ propolis groups, ${ }^{d} \mathrm{P}<0.05$ vs control.

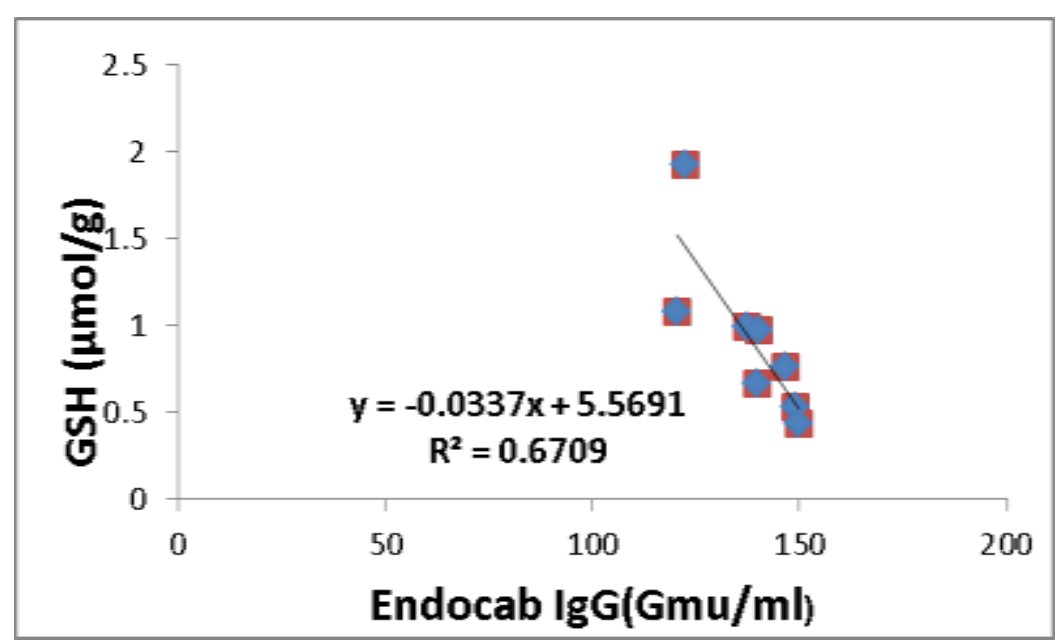

Fig (1): Scatter plot for regression line for correlation between Jejunal GSH level and circulating endotoxin core antibodies IGg (endocab) in Chlorpyrifos treated group 


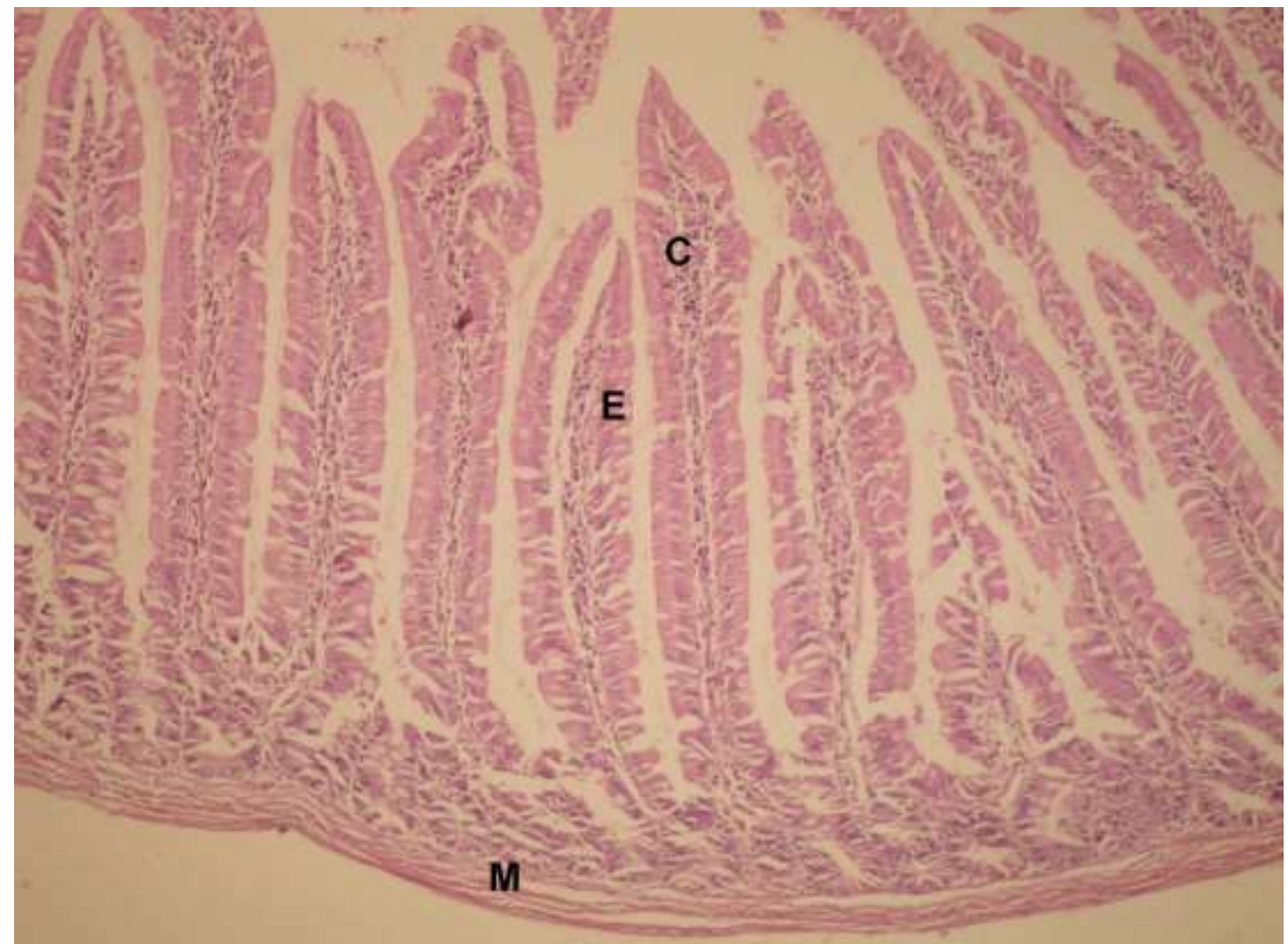

Fig (2): A photomicrograph of a section in a control rat's jejunum showing finger-like villi protruding in the intestinal lumen lined by simple columnar epithelium (E) with goblet cells. The submucosa consists of loose connective tissue with blood vessels (C), the muscle layer appears normal (M)

$(\mathrm{H} \& \mathrm{E} \times \mathbf{2 0 0})$

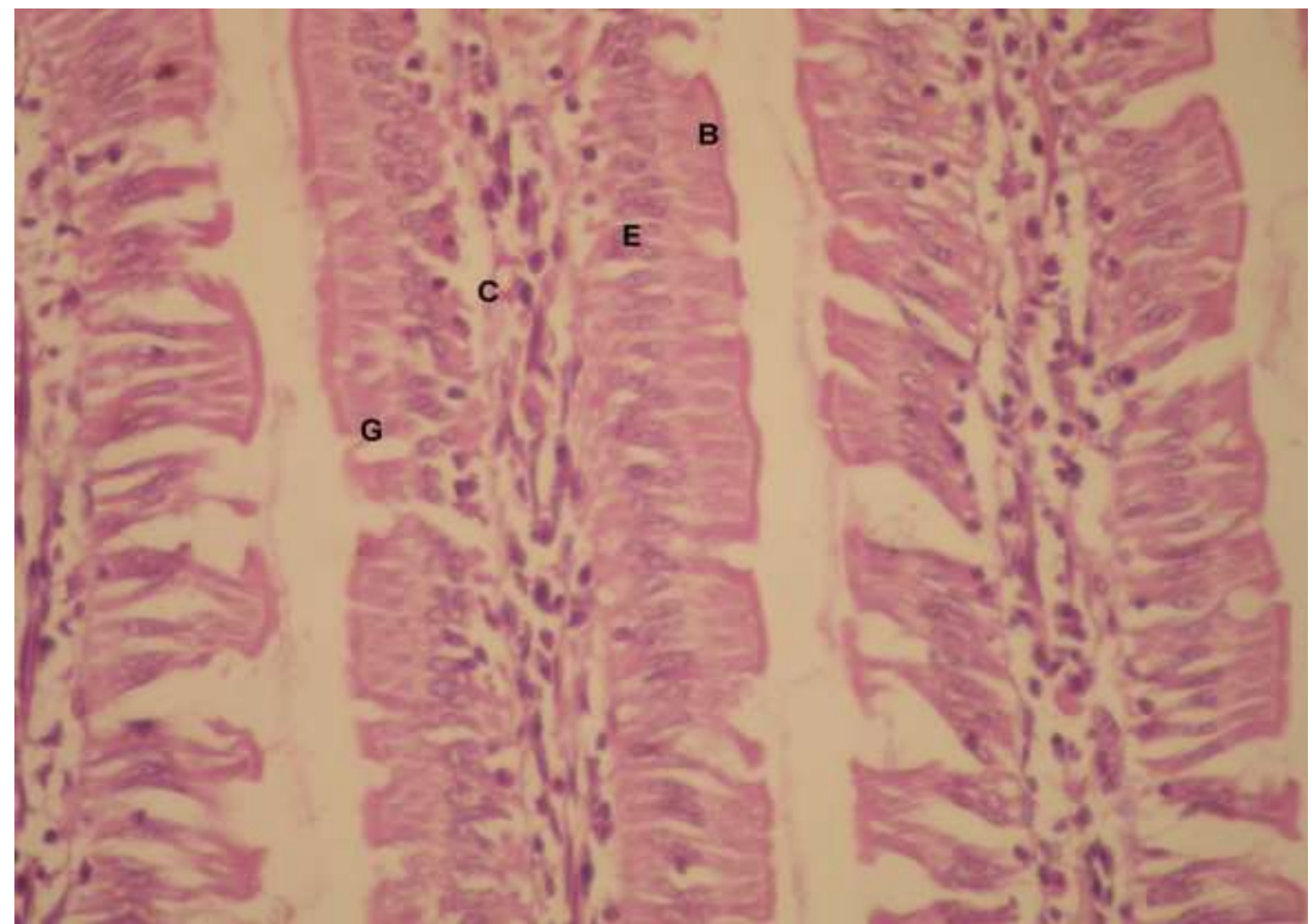

Fig (3): A photomicrograph of a section in a control rat's jejunum showing finger-like villi lined by simple columnar epithelium with basal oval nucli $(E)$ and brush border $(B)$, there are intersepted goblet cells (G). The submucosa consists of loose connective tissue with blood vesels (C) (H\&E $\times 400)$ 


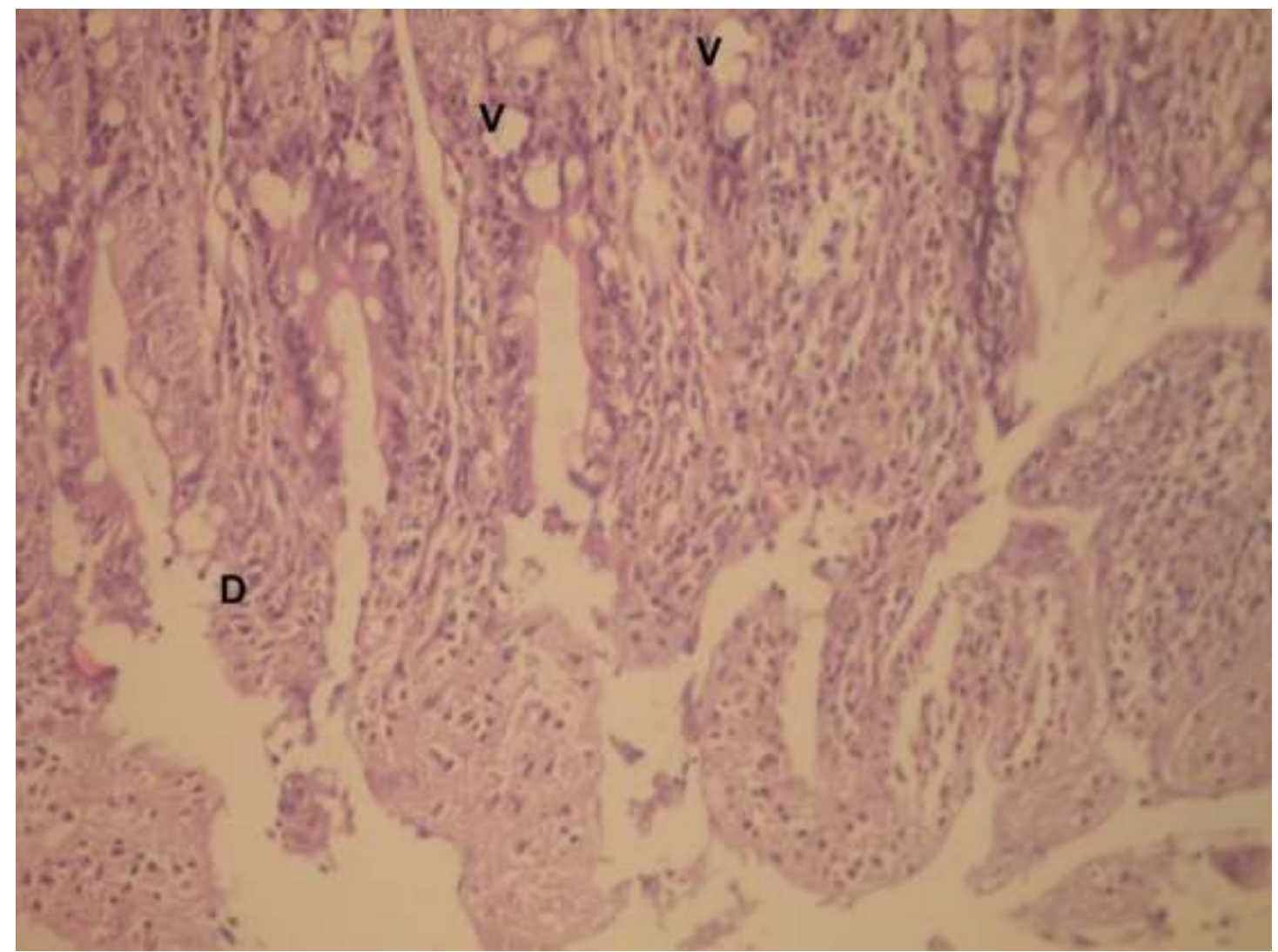

Fig (4): A photomicrograph of a section in jejunum of chlorpyrifos treated rat showing disruptedvilli (D) with loss of epithelium and apparent vaculation (V) (H\&E ×200)

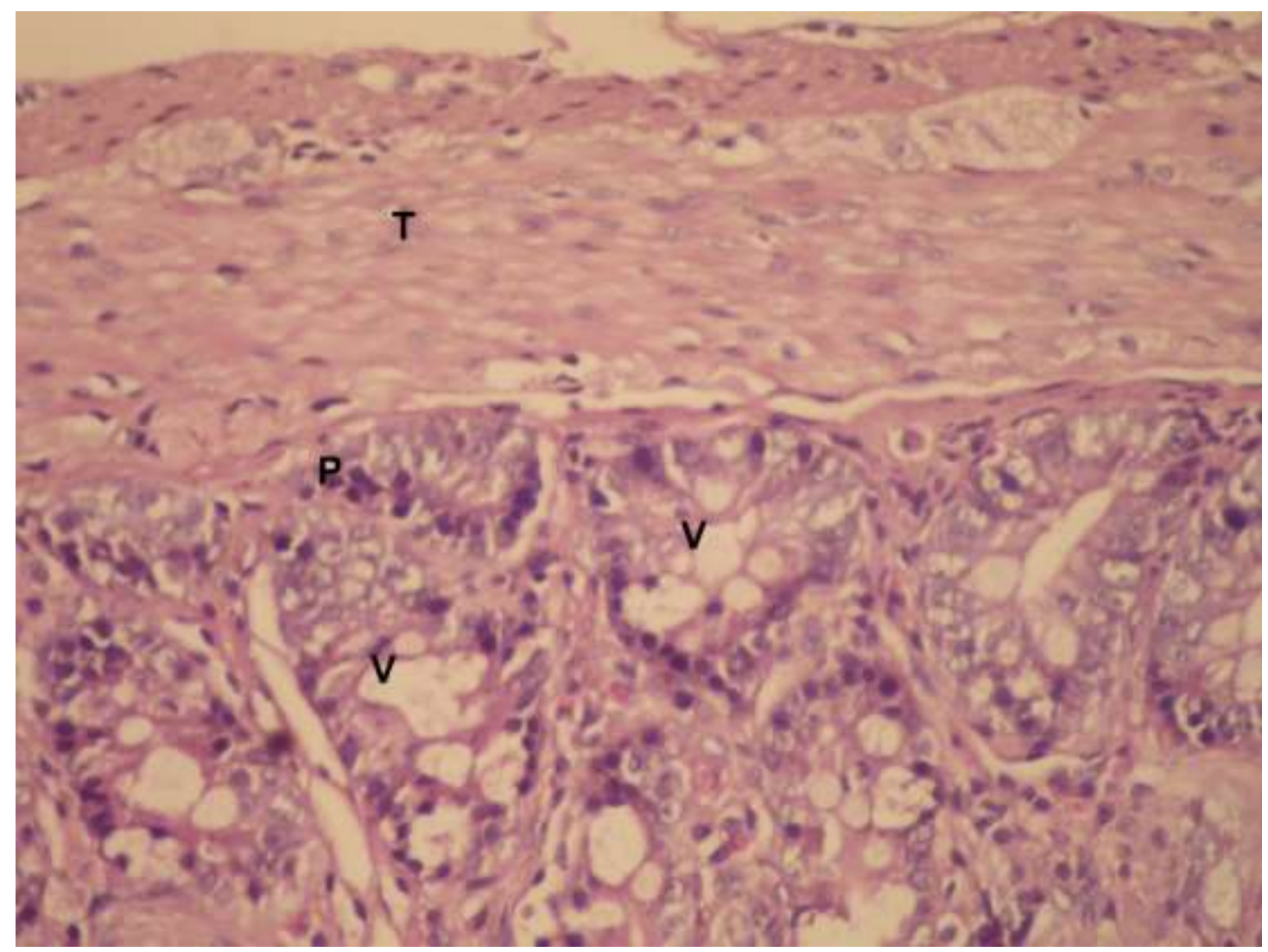

Fig (5): A photomicrograph of a section in jejunum of chlorpyrofos treated rat showing thickened and separated muscle fibers (T), dark stained pyknotic nucli (P) with apparent vaculation (V) (H\&E ×400). 


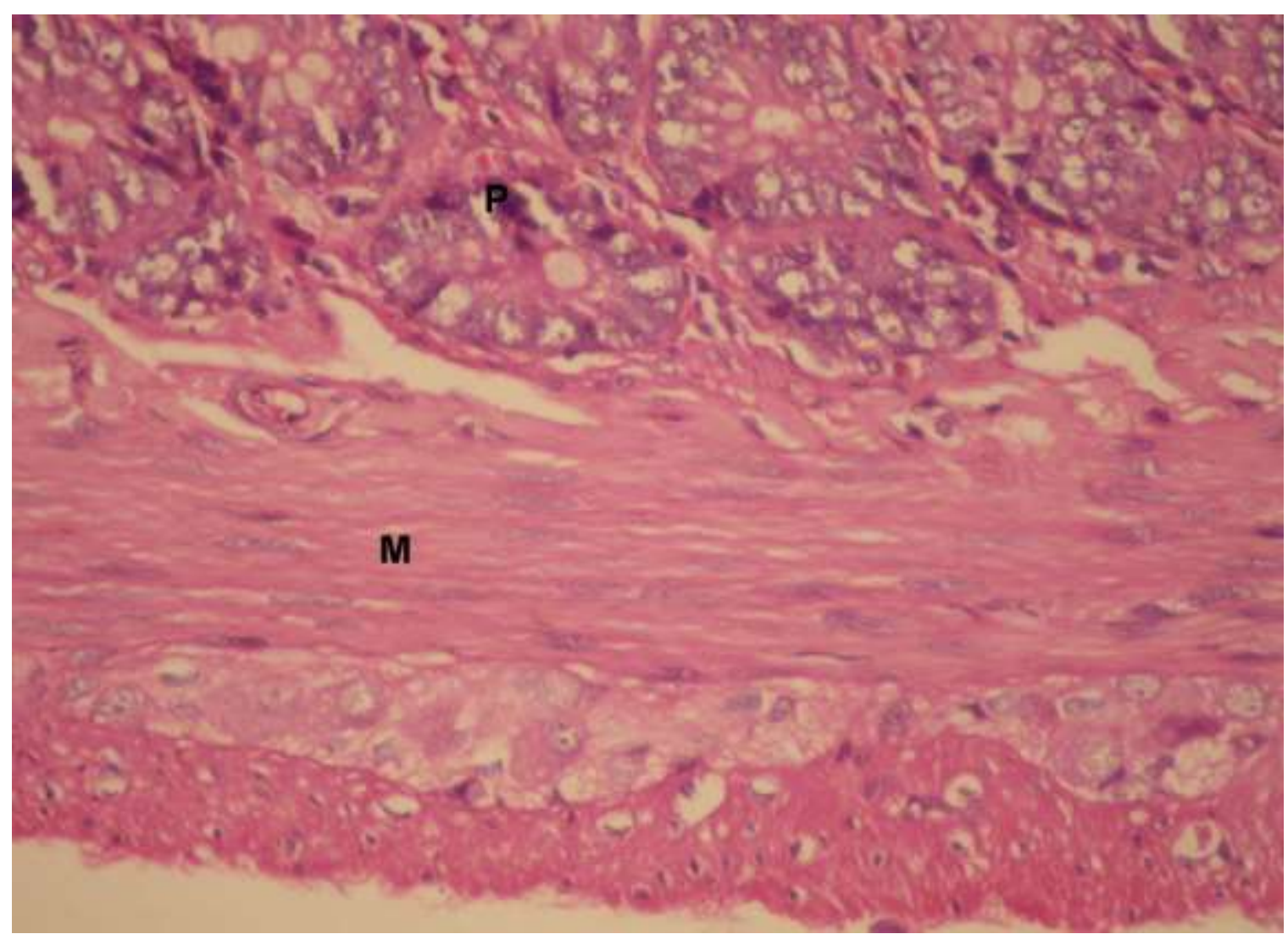

Fig (6): A photomicrograph of a section in jejunum of $\mathrm{CPF}+$ propolis treated rat showing less vaculation and pyknotic nucli (P). There is improvement in the muscle layer pathology $(\mathrm{H} \& \mathrm{E} \times 400)$.

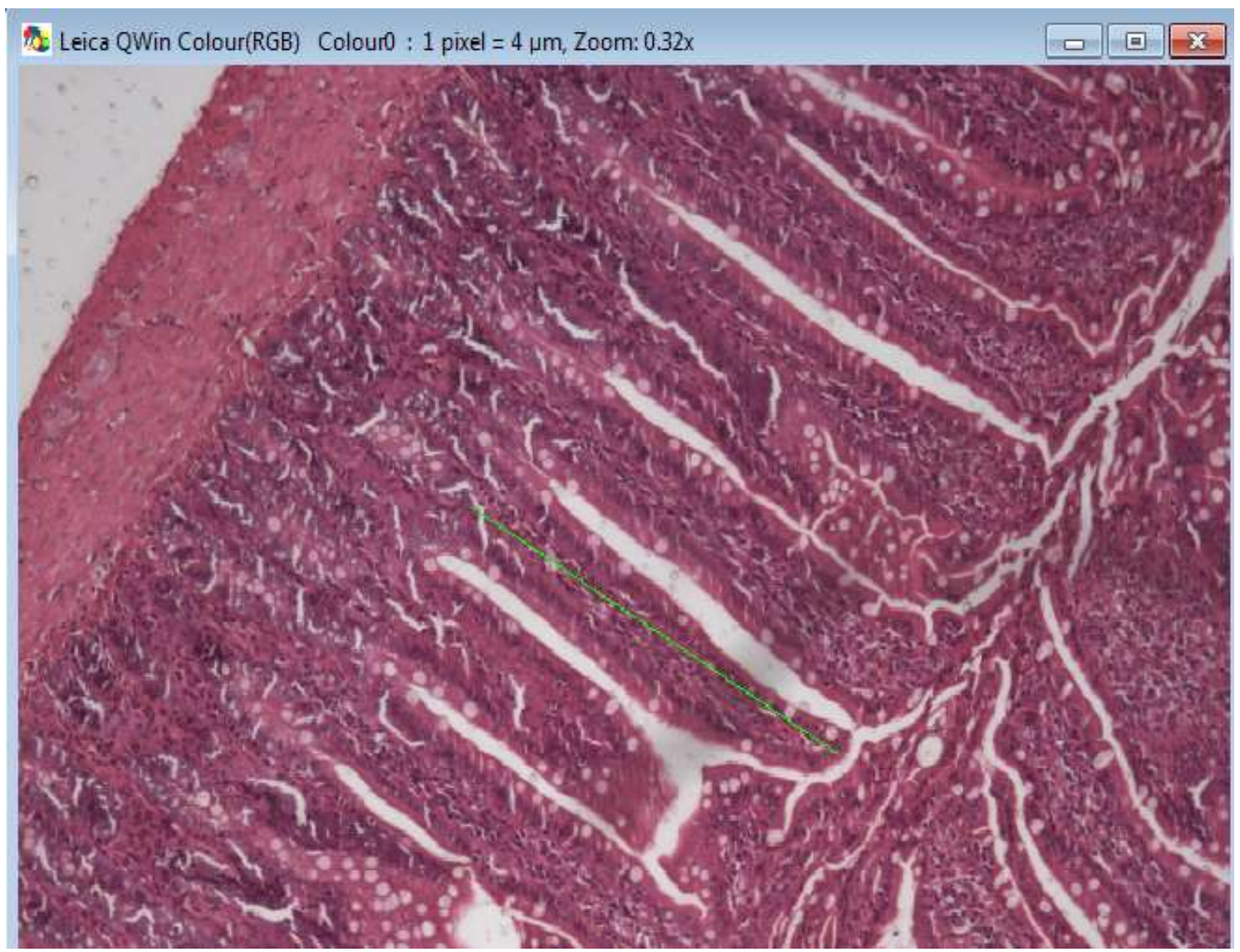

Fig (7): measurement of the villi height using the image analyzer computer system Leica Qwin $500($ H\&E $\times 100)$. 


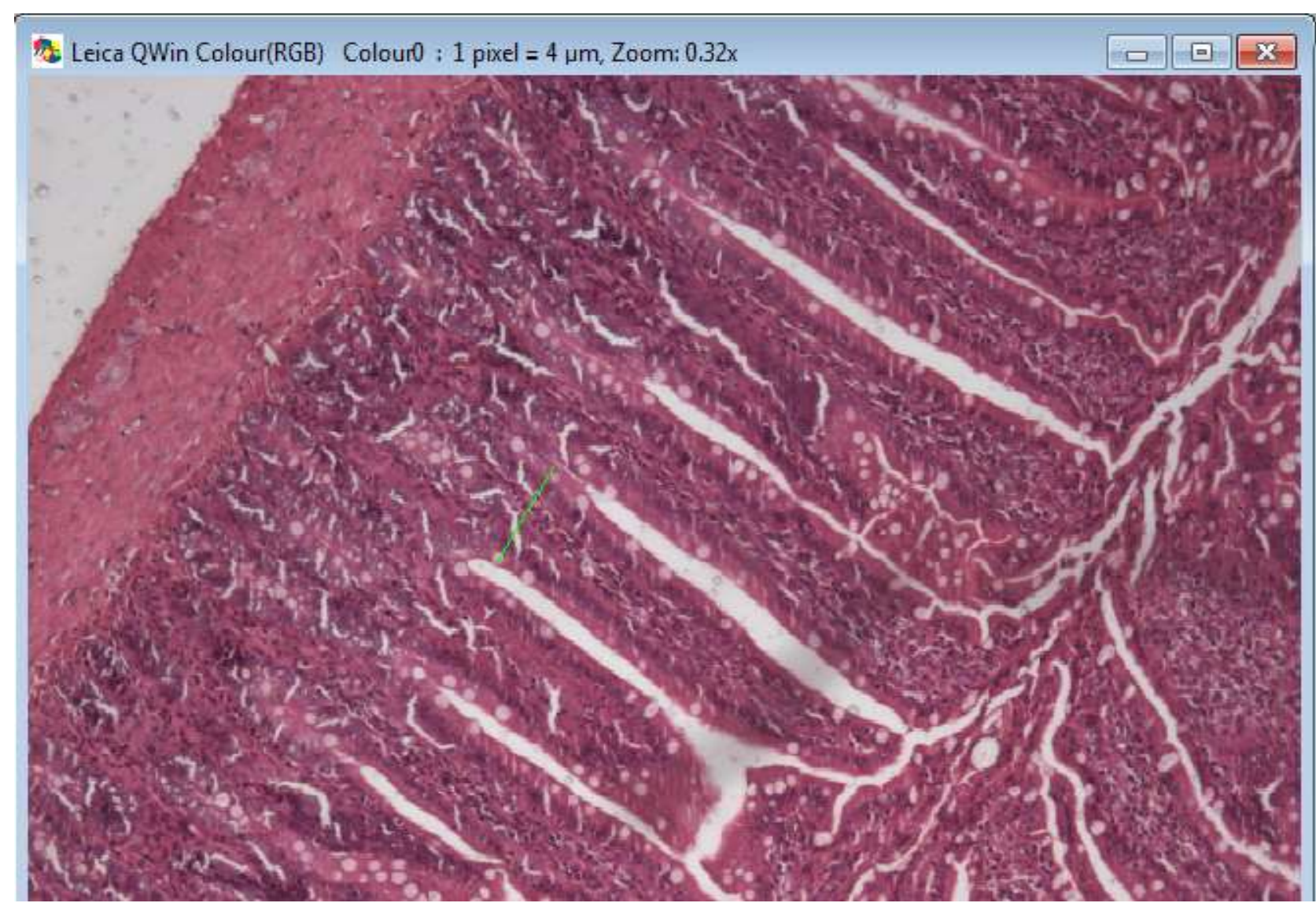

Fig (8): measurement of the villi height using the image analyzer computer system Leica Qwin 500 (H\&E ×100).

\section{Discussion}

Chlorpyrifos is an organophosphorus insecticide. Although it has been withdrawn from markets by the manufacturer, it is still widely used indoor for insect control and in agricultural workplace especially in lowmiddle income countries like Egypt. This has raised the concerns for the Potential adverse health impacts from inadvertent exposure to chlorpyrifos in segments of the population either from short-term high level exposure or long-term low-level exposure with consequent toxic effects (Farahat et al., 2010).

Chronic exposure to low levels of CPF occurs from food and water contamination, dermal contact and inhalation and it is well absorbed by ingestion and inhalation route. Once CPF has been absorbed, it promptly distributes to all organs and concentrates in lipid-rich tissues (EPA, 2000). Although the digestive tract is the first organ to come into contact with food contaminants, little is known about CPF's impact on the epithelial barrier (Tirelli et al., 2007).

The aim of this work was to study the toxic effects of chronic oral exposure to chlorpyrifos on jejunum of adult male albino rats and to evaluate the protective role of propolis through evaluation of serum citrulline level as a biomarker of gut epithelial cells injury, circulating endotoxin core antibodies (Endocab IgG) as marker for bacterial translocation, oxidative stress markers in jejunal tissue (GSH, MDA) as a possible underlying mechanism and histopathological examination for the jejunum tissue.

The results of this study showed highly significant decrease in the serum citrulline levels in chlorpyrifos group when compared with both control and chlorpyrifos+propolis.

Citrulline is the metabolic product of glutamine, and its related amino acids, and arginine.It is synthesized almost exclusively by the intestine. Its plasma level has been identified as a biomarker of the functional small bowel enterocyte mass (Crenn et al., 2011 and Vokurka et al., 2013). Injury to the small intestine can be measured by the decline in circulating citrulline levels, with lower values corresponding to more severe small intestinal damage. Serum citrulline has emerged recently as being the best tool in assessing small intestinal enterocyte mass, function and small bowel epithelial cell loss irrespective of the aetiology of the intestinal mucosal pathology and has been validated for quantitative enterocyte assessment in villous atrophy disease (Crenn et al., 2003). Measuring citrulline serum level has the advantage of being simple, low cost and not influenced by nutritional status, level of hypoalbuminaemia, or inflammatory status (Downs, 2010 and Brazał et al., 2014). 
The significant reduction in serum citrulline in chlorpyrifos treated group indicates injury in intestinal epithelium barrier which is crucial for maintaining homeostasis and preventing the passage of food antigens and luminal bacteria (Condette et al., 2014).

These results are in accordance with Tirelli et al. (2007) who reported that there were two studies have shown that CPF increases intestinal permeability: an ex vivo model using the single pass intestinal perfusion method (with exposure to $0.1,2$ and10 mM $\mathrm{CPF}$ for $2 \mathrm{~h}$ ) and an in vitro model based on an enterocyte cell line (with exposure to 30, 50 and 250 $\mathrm{mM}$ CPF)

Also, Condette et al. (2014) proved that perinatal exposure to chlorpyrifos has short and long impact on digestive system causing alteration of mucosal barrier and morphological alteration in structures which in turn is associated with elevated permeability and bacterial translocation.

In the intestine, the interplay between gut bacterial colonization, the epithelial barrier and the immune system has a crucial role in the development of intestinal function. Excessive intestinal permeability to macromolecules may favor the uncontrolled passage of antigens and the onset of intestinal inflammation or gastrointestinal disease (Camilleri et al., 2012). In this work circulating endotoxin core antibodies (Endocab IGg) assay has been done to investigate bacterial translocation due to disruption of epithelia barrier and endotoxemia which may trigger inflammatory responses (Gardiner et al., 1995). Immunoglobulin is physically a more stable molecule than endotoxin and the assay is not affected by contamination. Antibody responses are sustained and are more likely to reflect previous endotoxin exposure, overcoming the problem associated with single sampling and transient endotoxaemia (Barclay et al., 1989).

The results of this work revealed significant increase in the endocab IGg in chlorpyrifos treated group when compared with both control and chlorpyrifos+propolis group.

This can be explained by the fact that IgG show significant initial fall as evidence of bacterial translocation and endotoxin release due to binding to these endotoxins and consumption of these antibodies, however IgG EndoCab concentrations recover within hours as $20 \%$ of EndoCab IgG is present in the peripheral circulation and the remainder is available as interstitial antibody reserves which quickly reconstitute circulating levels. Exposure to endotoxin is reflected in a rise in IgG EndoCab concentrations which inturn reflects chronicity of endotoxin exposure over more than 20 day period and hyperproduction of antibody by sensitized plasma cells (Clements et al., 1998).
Endocab IgG was chosen as a marker for chronic endotoxemia because it is more seneitive than Endocab IgM which is present only in circulating blood and it falls in acute cases with more profound falls with chronicity (Goldie et al., 1995).

Histopathological examination of jejunum tissue of chlorpyrifos group showed disrupted villi, with vaculation, loss of epithelial cells and dark stained apoptotic nuclei. Morphometric measures revealed significant decrease in both height and width of villi when compared with control and $\mathrm{CPF}+$ propolis groups.

In this study, Jejunum epithelium was chosen since its anatomy and physiology enables more distinct cell kinetics and minute description of enterocytes than other parts of the gastrointestinal tract. In addition, it represents a very dynamic part of the gastrointestinal tract and its villi allow much more absorption (Driák et al., 2008)

Jejunal mucosa acts as an important barrier to toxic and harmful materials and protects an individual from different antigenic and inflammatory reactions. The epithelium of the small intestine is characterized by villi \& crypts. Villi are folds of the epithelium into the lumen with a core of lamina propria. Villi are tallest in the jejunum The villus epithelium is composed of enterocytes and goblet cells.Disruption of the above mentioned structures are associated with impaired intestinal barrier function and lead to the passage of intraluminal contents into the systemic circulation (Rahner et al., 2001; Saudi et al., 2009 and Suzuki and Hara, 2010). Moreover, the enteric bacteria and endotoxin reinforce the damage (Cani et al., 2009).

Ueno et al (2011) reported that decreased villous height and crypt depth in the jejunum were associated with decreased transmucosal resistance and increased permeability indicating intestinal barrier dysfunction

Condette et al. (2014) reported that chronic CPF exposure in rats has a strong impact on epithelial barrier with changes in the paracellular permeability rather than transcellular transport.

It is difficult to say the exact mechanism by which CPF induced its effect on epithelial barrier, however one of the suggested explanation that, CPF may modify the function of the enteric nervous system and its associated cholinergic signaling, which in turn may modulate epithelial barrier permeability.

This can be explained by Cameron and Perdue (2007) who reported that cholinergic signaling is involved in the regulation of barrier function. Moreover, Zhang and $\mathrm{Li}$ (2012) suggested that a cholinergic agonist could ameliorates liposaccharides (LPS) induced intestinal epithelial tight junction damage and hence paracellular transport is regulated by a cholinergic signaling. Chlorpyrifos oxon is known to inhibit acetylcholinesterase activity which increases the amount of acetylcholine in the synaptic space (Eaton et al., 2008). Consequently, we could suspect an overstimulation of acetylcholine receptors leading to a rise in nerve transmission. But CPF oxon has been described to block muscarinic receptors, reducing the potentially protective effect of acetylcholine on gut barrier dysfunction. (Liu et al., 2002) 
Ncibi et al. (2008) suggested that chlorpyrifos cause damage to the cellular molecules since it is lipophilic and can pass easily through the cells into the cytoplasm.

Another suggested underlying mechanism of CPF induced toxicity is oxidative stress (Ambali et al., 2010 a, b and Kanika et al., 2014). They stated that both acute and chronic CPF toxicity are due to induction of an oxidative stress state with formation of ROS.

Also, Yonar et al. (2014) considered CPF exposure to as a stressor substance. In addition, Mazzon et al. (2002) found that stress disrupts intestinal homeostasis and increase the intestinal permeability in rats.

In the current study we investigated the possible oxidative stress effect of CPF through estimation of reduced GSH and MDA in jejunal mucosa and the results revealed significant decrease in GSH and increase in MDA when compared with control and $\mathrm{CPF}+$ propolis groups.

These results were in agreement with those of El-Banna et al.(2009) and Aly et al. (2010) who stated that CPF induce toxicity by generating free radicals and altering antioxidant levels of the free radical scavenging enzyme activity. Also, El-Kashoury and Tag El-Din (2010) reported that CPF directly impaired endogenous antioxidants like reduced glutathione (GSH), and the activities of antioxidant enzymes which can lead to the development of oxidative stress in different tissues.

Moreover, Verma et al. (2007) found that CPF produces oxidative stress resulting in the accumulation of lipid peroxidation products in different organs of rats. Also, Attia et al. (2012) stated that CPF treatment for 70 days cause significant reduction in antioxidant enzyme activities and elevation in lipid peroxidation level. In addition, Yonar et al. (2014) stated that Lipid peroxidation is the initial step of cellular membrane damage.

Reduced gluthathion (GSH) is the most abundant low molecular weight thiol in

mammalian cells, serves as a crucial component of cellular antioxidant defences and. plays a key role in the detoxification of cellular free radicals, toxins and carcinogens (Henry et al., 2008). They participate in the elimination of ROS, acting both as a non-enzymatic oxygen radical scavenger and as a substrate for various enzymes such as GSH-Px (Tsukamoto et al., 2002). The epithelial cells of the jejunum are highly dependent on GSH to detoxify peroxidized lipids and reactive electrophils in the mucosal epithelium (Samiec et al., 2000). Glutathione (GSH) deficiency leads to increase susceptibility to oxidative injury and exacerbate degeneration of the epithelial cells of the jejunum (Martensson et al., 1990). This epithelial damage results in translocation of luminal content to the inner layers of the intestinal wall with disruption of normal intestinal function and permeability (Bischoff et al., 2014).

Malondialdehyde (MDA) is a biomarker for Lipid peroxidation which in turn is a valuable indicator of oxidative damage of cellular components. Most components of cellular structure and function are likely to be potential targets of oxidative damage, and the most susceptible substrates for autoxidation are polyunsaturated fatty acids of the cell membrane, which undergo rapid peroxidation. (Yonar et al., 2014)

In CPF Propolis group; co-administration of Propolis caused partial increase in serum citrulline level, decrease in Endocab IgG, increase in GSH, decrease in MDA, increase in both villi height and width and partial improvement of histopathological changes when compared with chlorpyrifos treated group.

This can be explained by that propolis (bee glue), which contains a variety of chemical compounds such as polyphenols (flavonoid aglycones, phenolic acids and their esters, phenolic aldehydes, alcohols, and ketones), quinones, coumarins, steroids amino acids, and inorganic compounds, has been proven to have antioxidant (Kanbur et al., 2009), antibacterial (Scazzocchio et al., 2006), anti-inflammatory, immunomodulatory and immunostimulant activities (Yang et al., 2014).

The antioxidant activity of propolis components is reported to be due to the reverse of consumption of glutathione (Castaldo and Capasso, 2002) and the direct radical scavenging effect (Mani et al., 2006).

In addition, Jasprica et al. (2007) stated that propolis alone cause decrease in the MDA level, as it can hinder membrane lipid peroxidation and free radical formation. This may explain our findings that MDA levels in $\mathrm{CPF}+$ propolis group was not significantly different from those of control group.

Moreover, Cetin et al. (2012) and Yang et al. (2014) reported that propolis can inhibit microorganism growth and promote immune-stimulation with increased levels of serum IgG and IgM humoral immunity, elicit high antibody titer, elicit high and persistent mucosal immunity and enhance cellular response.

However, the partial improvement of biochemical and histopathological findings in $\mathrm{CPF}+$ propolis group when compared with control and chlorpyrifos group may be attributed to that CPF induced the toxic effect on jejunum not only due to oxidative stress but also may be due to its blocking effect on muscrinic receptors in gut and hindering acetylcholine protective effect on barrier or due to direct cell membrane damage. This needs further studies and investigation

Another possible cause is that although propolis has antioxidant and anti bacterial effect, it was proven that propolis exert is antibacterial effect mainly on gram + ve bacteria (Stepanović et al., 2003) , while in our study a significant increase in the circulating enotoxin core antibodies (Endocab IgG) for 4 gram -ve bacteria was detected .

Moreover, the oxidative stress and endotoxemia seemed to be correlated together as reported by Shuhei and Shinobu (2006). They showed that oxidative stress induce epithelial barrier injury and bacterial 
translocation with endotoxemia which inturn seems to induce oxidative stress condition through decreasing the scavenger of free radicals or increasing mitochondrial ca load with impairment of mitochondrial function, loss of cellular structure and hence cell injury

This was proved in our study where a negative correlation between GSH level and Endocab IgG was detected which means that decrease in the GSH will cause more disruption of epithelia barrier and hence more bacterial translocation and increase of Endocab which inturn will cause more decrease in GSH.

\section{Conclusion}

Chronic exposure to Chlorpyrifos at a daily dose of $6.75 \mathrm{mg} / \mathrm{kg}$ (1/20 of the oral LD50) for 12 weeks causes disruption of epithelial barrier of jejunum with increased permeability evidenced by increased endotoxin core antibodies (Endocab IgG) due to bacterial translocation with decrease in citrulline level which is an indicator of eneterocyte cell mass and function. These effects may be due to CPF induction of oxidative stress state evidenced by decrease in GSH and increase in MDA. Propolis can partially ameliorate the toxic effect of CPF by decreasing oxidative stress.

\section{Recommendations}

-Increase awareness of exposed personnel such as farmers and workers towards the toxicological hazards of chlorpyrifos, proper handling of its products and applicable access to information about proper use, the precautions needed and using the simplest hygienic and protective measures.

-Encouragement of using propolyis as cheap, available and safe food supplement to decrease the risk of chlorpyrifos associated jejunal toxicity.

-Periodical clinical and laboratory examination of exposed workers is necessary.

-Other Clinical and experimental studies on protective effects of propolis are needed

\section{Acknowledgments}

The authors are grateful for dr/ Heba Elnegris assistant professor of histology in Histology and Cell Biology Department, Faculty of Medicine, Zagazig University, dr Nermin Assad ,assisstant professor in Pathology Department, Faculty of Dentistry, Cairo University, and dr/ Rasha Lofty, assistant professor in Biochemistry Department, Faculty of Medicine, Zagazig University for their great effort in facilitating the equipments and kits needed for this work.

\section{References}

Abdelaziz KB, El Makawy AI, Abd Elsalam AZ et al., (2010): Genotoxicity of Chlorpyrifos and the Antimutagenic Role of Lettuce Leaves in Male Mice. Comunicata Scientiae, 1(2): 137145

Aly N, El-Gendy K, Mahmoud F et al., (2010): Protective effect of vitamin $\mathrm{C}$ against chlorpyrifos oxidative stress in male mice. Pest Biochem Physiol. 97: 7-12.

Ambali SF, Abubakar AT, Shittu M et al., (2010a): Chlorpyrifos-induced alteration of hematological parameters in Wistar rats:
Ameliorative effect of zinc. Research Journal of Environmental Toxicology, 4(2): 55-66.

Ambali SF, Abubakar AT, Shittu M et al., (2010b): Ameliorative Effect of Zinc on ChlorpyrifosInduced Erythrocyte Fragility in Wistar Rats. New York Science Journal, 3(5): 117-122.

Attia AA, ElMazoudy R H and El-Shenawy N S (2012): Antioxidant role of propolis extract against oxidative damage of testicular tissue induced by insecticide chlorpyrifos in rats. Pest Biochem Physiol. 103: 87-93.

Bancroft G and Stevens A (1996): Theory and practice of histopathological technique. In: Churchill Livingstone. By Stewart J and Edward B. 4th ed., Edinburgh, London, Melbourne and New York 99-112.

Bancroft JD and Gamble M (2002): Theory and Practice of Histological Technique. 5th edition. Edinburg and London: Churchill Livingstone

Barclay GR, Scott BB, Wright IH et al. (1989): Changes in anti-endotoxin IgG antibody and endotoxaemia in three cases of Gram-negative septic shock. Circ Shock. 29:93-106.

Barclay GR, Scott BB, Wright IH et al., (1989): Changes in anti-endotoxin IgG antibody and endotoxaemia in three cases of Gram-negative septic shock. Circ Shock; 29:93-106.

Barzał JA, Szczylik C, Rzepecki P et al.,(2014): Plasma citrulline level as a biomarker for cancer therapy-induced small bowel mucosal damage, Acta Biochemica Polanica, 61(4); 615:631.

Bhadauria M, Shukla S, Mathur R et al., (2008): Hepatic endogenous defense potential of propolis after mercury. Integrative Zoology; 4: 311-321

Bischoff S, Barbara G, Buurman W et al., (2014): Intestinal permeability - a new target for disease prevention and therapy. BMC Gastroenterology 2014, 14:189

Busby AL, Kousba AA and Timchalk C (2004): The In Vivo Quantitation of Diazinon, Chlorpyrifos and their Major Metabolites in Rat Blood for the Refinement of a Physiologically-based Pharmacokinetic/pharmacodynamic Models. Journal of Undergraduate Research Volume IV: 36-40.

Cameron HL and Perdue MH (2007): Muscarinic acetylcholine receptor activation increases transcellular transport of macromolecules across mouse and human intestinal epithelium in vitro. Neurogastroenterol Motil. 19: 47-56.

Camilleri M, Lasch K and Zhou W (2012): Irritable bowel syndrome: methods, mechanisms, and pathophysiology, the confluence of increased permeability, inflammation, and pain in irritable bowel syndrome. Am J Physiol Gastrointest Liver Physiol 303: G775-785.

Cani P D, Possemiers S, Van de Wiele T et al., (2009): Changes in gut microbiota control inflammation in obese mice through a 
mechanism involving GLP-2-driven improvement of gut permeability. Gut, 58(8):1091-103.

Cani P, Possemiers S, Van de Wiele T et al., (2009): Changes in gut microbiota control inflammation in obese mice through a mechanism involving GLP-2-driven improvement of gut permeability. Gut. 58(8):1091-103.

Castaldo S and Capasso F (2002): Propolis, an old remedy used in modern medicine. Fitoterapia. 73:1-6.

Cetin E, Silici S andGuclu B (2010): Effects of diets containing different concentrations of propolis on hematological and immunological variables in laying hens. Poultry Science, 89:1703-1708

Clements W, Erwin P, McCaigue M et al., (1998): Conclusive evidence of endotoxaemia in biliary obstruction. Gut .42:293-299

Condette CJ, Bach V, Mayeur C etal., (2015): Chlorpyrifos Exposure During Perinatal Period Affects Intestinal Microbiota Associated With Delay of Maturation of Digestive Tract in Rats. J Pediatr Gastroenterol Nutr. 61(1):30-40

Condette CJ, Khorsi-Cauet H, Morliere P et al., (2014): Increased Gut Permeability and Bacterial Translocation after Chronic Chlorpyrifos Exposure in Rats. PLOS ONE, 9(7): e102217

Cook TJ and Shenoy SS (2003): Intestinal permeability of chlorpyrifos using the single-pass intestinal perfusion method in the rat. Toxicol. 184: 125-133.

Crenn P, Hanachi M, Neveux N et al., (2011): Circulating citrulline levels: a biomarker for intestinal functionality assesment. Ann Biol Clin 69: 513-521

Crenn P, Vahedi K and Lavergne Slove A (2003): Plasma citrulline: a marker of enterocyte mass in villous atrophy-associated small bowel disease. Gastroenterology 124: 1210-1219.

Downs JH (2010): The gastrointestinal tract and HIV pathogenesis. S Afr J Clin Nutr 23(1): 65-68

Driák1 D, Österreicher J, Vávrová J et al., (2008): Morphological Changes of Rat Jejunum after Whole Body $\gamma$-irradiation and Their Impact in Biodosimetry. Physiol. Res. 57: 475-479.

Eaton DL, Daroff RB, Autrup $\mathrm{H}$ et al., (2008): Review of the Toxicology of Chlorpyrifos with an Emphasis on Human Exposure and Neurodevelopment. Critical Reviews in Toxicology, S2:1-125

El-Banna S G, Attia A M, Hafez A M et al., (2009): Effect of garlic consumption on blood lipid and oxidant/antioxidant parameters in rat males exposed to chlorpyrifos. Slovak J. Anim. Sci., 42(3):111 - 117.

Elelaimy IA, Ibrahim HM, Abdel Ghaffar FR et al., (2012): Evaluation of sub-chronic chlorpyrifos poisoning on immunological and biochemical changes in rats and protective effect of eugenol. J App Pharmacut Sci. 2(6): 51-61.

Environmental Protection Agency (EPA) (2000): Toxicology chapter for chlorpyrifos. Pesticides and toxic substances, Office of pesticides programs, U.S. Government printing office, Washington.

Farahat FM, Fenske R A, Olson JR et al., (2010): Chlorpyrifos Exposures in Egyptian Cotton Field Workers. Neurotoxicol. 31(3): 297-304.

Flaskos J (2009): The developmental neurotoxicity of organophosphorus insecticides: A direct role for the oxon metabolites. Toxicology Letters, 209 (1): 86-93

Gardiner KR, Halliday MI, Barclay GR, et al., (1995): Significance of systemic endotoxaemia in inflammatory bowel disease. Gut, 36:897901.

Goel A, Dani V and Dhawan DK (2005): Protective effects of zinc on lipid peroxidation, antioxidant enzymes and hepatic histoarchitecture in chlorpyrifos-induced toxicity. Chem Biol Interact. 156(2-3):131140

Goel A, Dani V and Dhawan DK (2006): Role of zinc in mitigating the toxic effects of chlorpyrifos on hematological alterations and electron microscopic observations in rat blood. Biometals, 19(5):483-92

Goldie AS, Fearon KCH, Ross JA, et al., (1995): Natural cytokine antagonists and endogenous antiendotoxin core antibodies in sepsis syndrome. JAMA; 274:172-7.

Henry J, Hongqiao Z and Alessandra R (2009): Glutathione: Overview of its protective roles, measurement, and biosynthesis. Mol Aspects Med. 30(1-2): 1-12.

Jasprica D, Mornar A, Debeljak Z et al., (2007): In vivo study of propolis supplementation effects on antioxidative status and red blood cells, J. Ethnopharmacol., 110 548-554.

Kanbur M, Eraslan G and Silici S (2009): Antioxidant effect of propolis against exposure to propetamphos in rats. Ecotox Environ Saf. 72:909-915.

Kanika A, Devinder S and Singla K (2014): Studies on the effect of oxidative stress induced by chlorpyrifos on antioxidant hepatic enzymes in rat. World J Pharmacy and Pharmaceut Sci. 3(11): 523-533.

Khalil ML (2006): Biological activity of bee propolis in health and disease. Asian Pac J Cancer Prev.7(1):22-31.

Liu J, Chakraborti T and Pope C (2002): In vitro effects of organophosphorus anticholinesterases on muscarinic receptormediated inhibition of acetylcholine release in rat striatum. Toxicol Appl Pharmacol. 178: 102-108.

Mani F, Damasceno HC, Novelli EL et al., (2006): Propolis: Effect of different concentrations, extracts and intake period on seric 
biochemical variables. J Ethnopharmacol. 105:95-98.

Martensson J, Jaint A and Meister A (1990): Glutathione is required for intestinal function (mitochondrial buthionine sulfoximine glutathione monoester pancreas). Proc. Natl. Acad. Sci. 87: 1715-1719

Mazzon E, Sturniolo G, Puzzolo D et al., (2002): Effect of stress on the paracellular barrier in the rat ileum. Gut. 51: 507-513.

Ncibi S, Ben Othman M, Akacha A et al., (2008): Opuntia ficus indica extract protects against chlorpyrifos-induced damage on mice liver. Food Chem Toxicol., 46(2):797-802.

Rahner C, Mitic LL and Anderson JM (2001): Heterogeneity in expression and subcellular localization of claudins 2, 3, 4, and 5 in the rat liver, pancreas, and gut. Gastroenterology, 120(2):411-422

Samiec P L, Dahm L J and Jones D P (2000): Glutathione S-transferase in mucus of rat small intestine. Toxicol. Sci. 54: 52-59.

Sandhu MA, Saeed AA, Khilji MS et al., (2013): Genotoxicity evaluation of chlorpyrifos: a gender related approach in regular toxicity testing. J Toxicol Sci. 38(2):237-244

Saudi W, Khan J and Islam MN (2009): Small intestinal morphology and permeability in chronic water avoidance stress in rats. I M J. 16(2), 87-91

Scazzocchio F, D'Auria F, Alessandrini D et al., (2006): Multifactorial aspects of antimicrobial activity of propolis. Microbiol Res.161(4): 327-333.

Shuhei S and Shinobu F (2006): Oxidative stress and septic shock:metabolic aspects of oxygen derived free radicals generated in the liver during endotoxemia. FEMS Immunol Med Microbiol. 47: 167-177

Stepanović S, Antić N, Dakić I et al., (2003): In vitro antimicrobial activity of propolis and synergism between propolis and antimicrobial drugs. Microbiol. Res. 158:353-357

Suzuki T and Hara H (2010): Dietary fat and bile juice, but not obesity, are responsible for the increase in small intestinal permeability induced through the suppression of tight junction protein expression in LETO and OLETF rats. Nutr Metab (Lond), 12;7-19

Tian Y, Ishikawa H, Yamaguchi T et al., (2005): Teratogenicity and developmental toxicity of chlorpyrifos, Maternal exposure during organogenesis in mice. Reprod Toxicol. 20(2):267-270.

Tietze F (1969): Enzymic method for quantitative determination of nanogram amounts of total and oxidized glutathione: applications to mammalian blood and other tissues. Anal. Biochem. 27(3): 502-522.

Tirelli V, Catone T, Turco L et al., (2007): Effects of the pesticide chlorpyrifos on an in vitro model of intestinal barrier. Toxicol In Vitro 21: 308313.

Tsukamoto M, Tampo Y and Sawada M (2002): Paraquat induced oxidative stress and dysfunction of the glutathione redox cycle in pulmonary microvascular endothelial cells. Toxicol Appl Pharmacol. 178:82-87.

Tsukamoto M, Tampo Y, Sawada M et al.,(2002): Paraquat induced oxidative stress and dysfunction of the glutathione redox cycle in pulmonary microvascular endothelial cells. Toxicol Appl Pharmacol., 178:82-87.

Ueno PM, Oriá RB, Maier EA et al., (2011): Alanylglutamine promotes intestinal epithelial cell homeostasis in vitro and in a murine model of weanling undernutrition. Am J Physiol Gastrointest Liver Physiol. 301(4):G612-22.

Verma R S, Mehta A and Srivastava N (2007): In vivo chlorpyrifos induced oxidative stress: attenuation by antioxidant vitamins. Pest. Biochem. Physiol., 88: 191-196.

Vokurka S, Svoboda T, Rajdl D et al., (2013): Serum citrulline levels as a marker of enterocyte function in patients after allogeneic hematopoietic stem cells transplantation - a pilot study. Med Sci Monit.19:81-85

Yang T, Deqing W, Yuanliang $\mathrm{H}$ et al., (2014): The Immunological Enhancement Activity ofPropolis Flavonoids Liposome In Vitro and In Vivo. Evidence-Based Complementary and Alternative Medicine: 8 .

Yonar ME, Yonar SM, Çoban MZ, et al., (2014): Antioxidant effect of propolis against exposure to chromium in Cyprinus carpio. Environ Toxicol. 29(2):155-64.

Zhang Y and Li J (2012): Carbachol ameliorates lipopolysaccharide-induced intestinal epithelial tight junction damage by downregulating NF-kappabeta and myosin lightchain kinase pathways. Biochem Biophys Res Commun. 428: 321-326. 


\section{الملخص العربيى

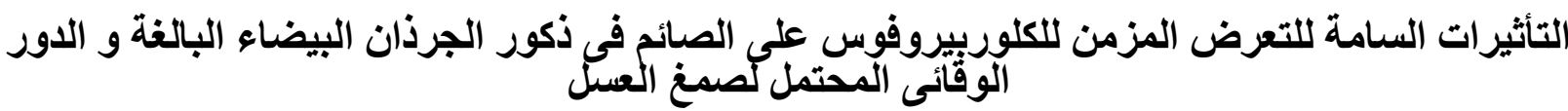

\section{يارا محمد الفخراني و اميمه ابراهيم عبد الحميدا}

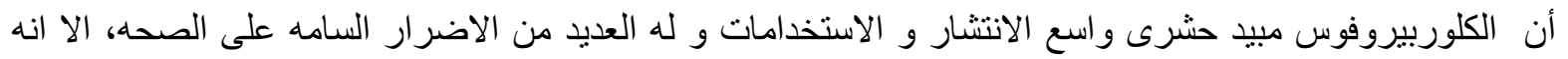

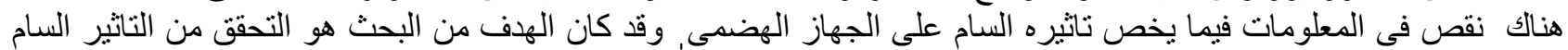

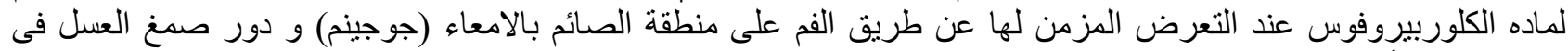

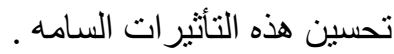

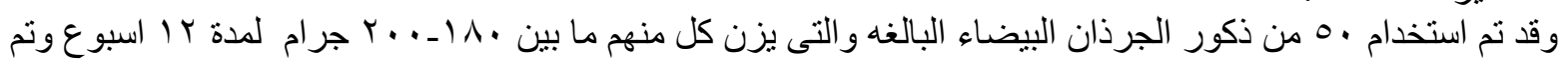
تقسيمهم الى ع مجمو عات كالاتى:

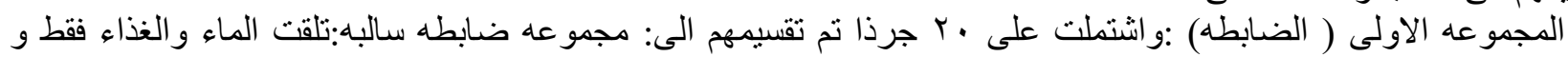

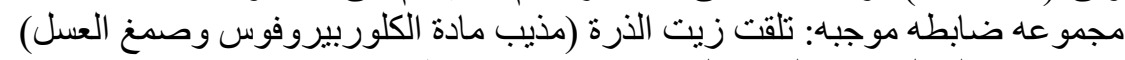

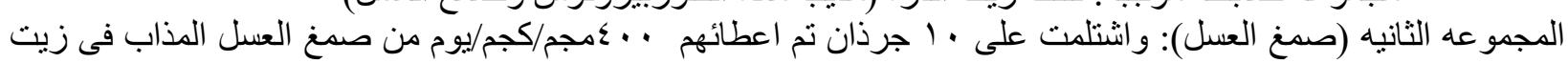

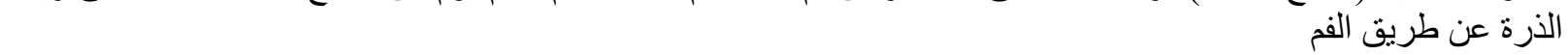
المجموعه الثالثة (الكلوربيروفوس):و اشتملت على • ل جرذان نم اعطائهم 6.75 مجم/كجم/يوم من الكلوربيروفوس مذاب فى

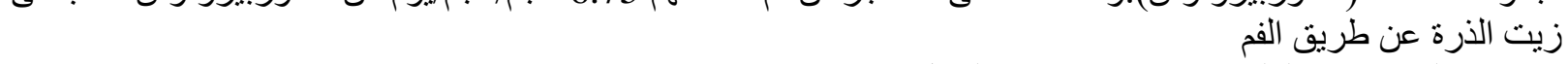

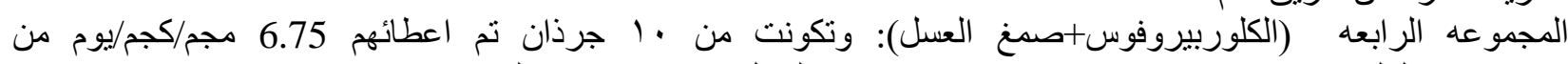

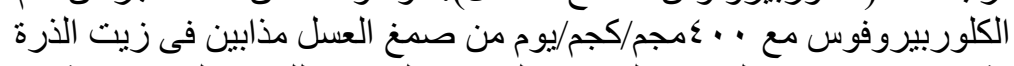

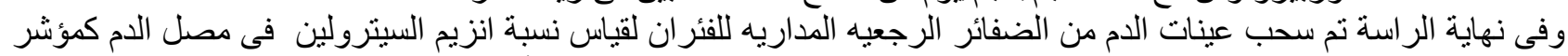

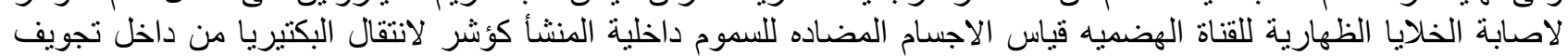

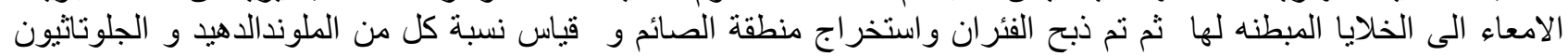

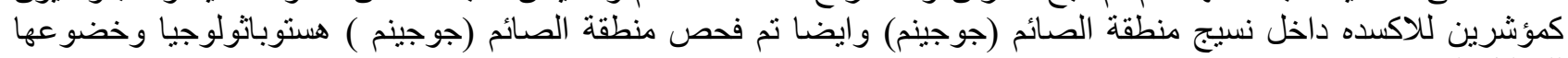

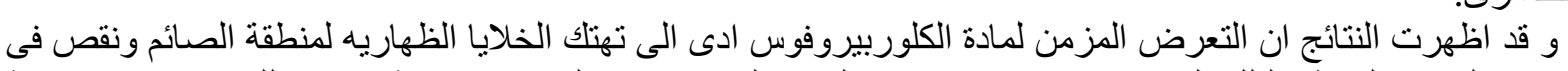

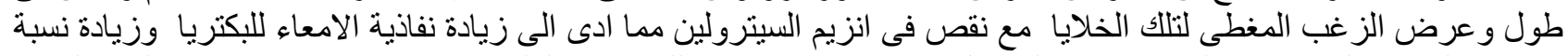

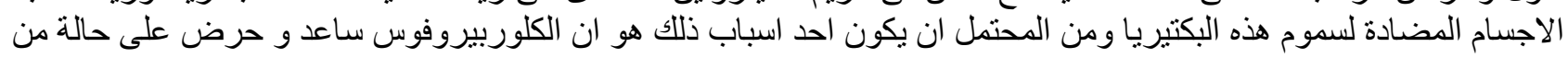

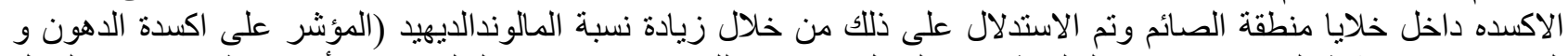

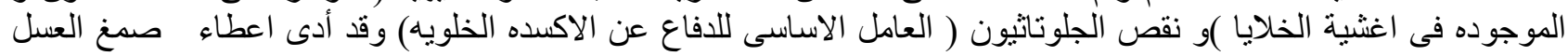

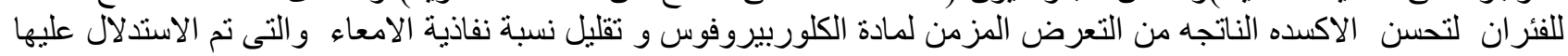

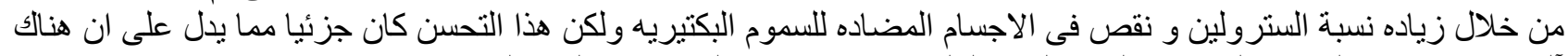

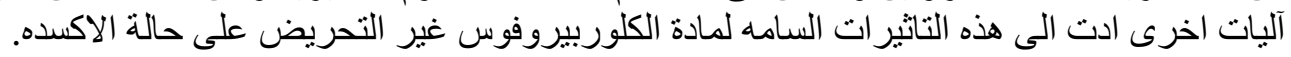

